\title{
Differentiation Effect of Two Alkaloid Fractions from Vietnamese Lycopodiaceae on Mouse Neural Stem Cells
}

\section{Hanh-Nguyen Thi Tran ${ }^{1}$, Huyen-Trang Thi Nguyen ${ }^{1}$, Dinh Hoang Nguyen ${ }^{1}$, Thuy Thi La ${ }^{1}$, Kim-Thanh Thi Nguyen ${ }^{1}$, Tien Dat Nguyen ${ }^{3}$, Quang Huy Nguyen ${ }^{1,2}$, Lai Thanh Nguyen ${ }^{1}$, My Hanh Thi Hoang ${ }^{1, *}$}

${ }^{1}$ Faculty of Biology, University of Science, Vietnam National University, Hanoi (VNU), Hanoi 10000, Vietnam

${ }^{2}$ National Key Laboratory of Enzyme and Protein Technology, University of Science, Vietnam National University, Hanoi (VNU), Hanoi 10000, Vietnam

${ }^{3}$ Center for Research and Technology Transfer, Vietnam Academy of Science and Technology, Hanoi 10000, Vietnam

Received - January 13, 2022; Revision - February 07, 2022; Accepted - February 22, 2022

Available Online - February 28, 2022

DOI: http://dx.doi.org/10.18006/2022.10(1).64.72

\section{KEYWORDS}

Lycopodium clavatum

Huperzia serrata

Lycopodium Alkaloid

Neuronal Disease

Mouse Neural Stem Cell

\begin{abstract}
Various Lycopodium alkaloids have been studied for their various biological activities including antiinflammatory, antioxidant, immunomodulatory, and neuroprotective activities. Moreover, these alkaloid compounds have high potential in the treatment of neuron degenerative disease. This study has been carried out to test the effect of Huperzia serrata (Thunb.) Trevis, and Lycopodium clavatum L alkaloid fractions on the mouse neural stem cells (NSCs). Firstly, the alkaloid fractions were used to verify its toxicity on NSCs. The multiple concentrations of alkaloid fractions from $H$. serrata $(0.044 ; 0.088 ; 0.175 ; 0.35 ; 0.7 ; 1.4$ $\mathrm{mg} / \mathrm{ml})$ and $L$. clavatum $(0.031 ; 0.063 ; 0.125 ; 0.25 ; 0.50 ; 1.0 ; 2.0 \mathrm{mg} / \mathrm{ml})$ have been used for the treatment of NSCs at period of $48 \mathrm{~h}$ incubation. Results of the study suggested that the $\mathrm{IC}_{50}$ value of $H$. serrata and $L$. clavatum was $0.56 \mathrm{mg} / \mathrm{ml}$ and $0.50 \mathrm{mg} / \mathrm{ml}$, respectively. Then, the NSCs were differentiated in the presence of 5 and $10 \mu \mathrm{g} / \mathrm{ml}$ of alkaloid fraction from $H$. serrata; 0.625 and $1.25 \mu \mathrm{g} / \mathrm{ml}$ of alkaloid fraction from $L$. clavatum for 6 days. Here, we observed the primary NSCs treated with alkaloid fraction extract from $H$. serrata showed the increased gene expression level of early neuron TUBB3 and neuron-specific cytoskeleton $M A P 2$. On the other hand, the L. clavatum alkaloid fraction increased the expression of neural stem cell marker genes (Nestin and $P A X 6$ ) and decreased neuron marker genes. In conclusion, these results established that alkaloid fraction from $H$. serrata promoted differentiation of the mouse NSCs to neuron cells, and $L$. clavatum extract had a capacity for stemness maintenance.
\end{abstract}

* Corresponding author

E-mail: hoangthimyhanh@hus.edu.vn (My Hanh Thi Hoang)

Peer review under responsibility of Journal of Experimental Biology and Agricultural Sciences.

Production and Hosting by Horizon Publisher India [HPI] (http://www.horizonpublisherindia.in/).

All rights reserved.
All the articles published by Journal of Experimental Biology and Agricultural Sciences are licensed under a Creative Commons Attribution-NonCommercial 4.0 International License Based on a work at www.jebas.org.

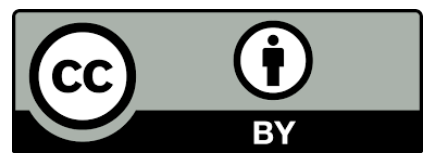




\section{Introduction}

Neural stem cells (NSCs), located in the central nervous system, are multipotent cells that can self-renew, proliferate and differentiate into neurons and glial cells (Fujita 2003; Noctor et al. 2001; Takouda et al. 2017). NSCs are present not only in the developing brain but also in specific areas such as the subventricular zone (SVZ) and hippocampus of the adult brain (Temple 2001; Gage 2000). Recent studies indicate that NSCs can be activated after neuronal injury and migrate to the injured sites to replace the lost neurons (Nakatomi et al. 2002; Russo et al. 2011). NSCs can be cultured as neurospheres and later on develop into an in vitro neural network. Primary NSCs culture provides an in vitro model to identify drugs that can protect NSCs or increase neurogenesis from NSCs. This raised the potential for the treatment of neural damage and neurodegenerative diseases (Gage 2000).

The Lycopodiaceae plants belong to club moss, mainly native to tropical mountains characterized by low evergreen herbs with needle-like or scale-like leaves. The Lycopodiaceae has been widely known as the traditional herbal medicine for a long time to treat medical ailments such as swelling, rheumatic fever, myasthenia gravis, schizophrenia (Ma and Gang 2004). These plants are rich in alkaloids that have high potential bioactivity properties with a range of applications in therapy and research. The lycopodium alkaloids have a unique structure of heterocyclic skeletons such as C16N1, C16N2, and C27N3. Until now, more than 400 lycopodium alkaloids have been described (Kitajima and Takayama 2011; Siengalewicz et al. 2013). The Lycopodium alkaloids have been shown various biological activities such as anticancer, antiviral, anti-inflammatory, hepatoprotective, and immunomodulatory activities. Recently, these alkaloids have been used to treat an aneurysm, chronic lung, and bronchial diseases also. Further, most of the alkaloids derived from Lycopodium were demonstrated their potential effects on neuron diseases (Ayer 1991; Zangara 2003; Kitajima and Takayama 2011; Siengalewicz et al. 2013). Huperzine A was extracted from H. serrata (Thunb.) Trevis and used as a folk medicine in the treatment of inflammation, swelling, and fever. The scientific evidence showed that these compounds also have other pharmacological activities such as anti-inflammation, antioxidation, protection of cellular organelles from some neurotoxic, and regulation of nerve growth factor (NGF) (Wang and Tang 2007; Zhang et al. 2008; Wang et al. 2011). Huperzine $A$ is a potent, specific, selective, and reversible inhibitor of acetylcholinesterase (AChE) (Friedli and Inestrosa 2021). This compound also has some effects on the learning and memory of animals. Li et al. (2021) reported the clinical effect of Huperzine A on elderly patients with vascular dementia. The result indicated that the co-treatment of Huperzine A and hyperbaric oxygen had a significant effect on cognitive function and serum hypoxia-inducible factor- $1 \alpha$ level ( $\mathrm{Li}$ et al.
2021). Using the meta-analysis of randomized clinical trials on Alzheimer's disease patients indicated that Huperzine A seemed to have significant effects on cognitive as well as activities of daily living, and improved global clinical assessment (Yang et al. 2013). L. clavatum is a rich source of alkaloids and triterpenoids. Recently, Dymek et al. (2021) developed a technique to extract L. clavatum, $L$. annotinum, and $H$. selago active ingredients by using the pressurized liquid extraction method. These methanolic extracts showed bioactivity as anti-AChE (Dymek et al. 2021). Three new triterpenoids of L. clavatum were isolated from the methanol extract via combined chromatographic separation techniques. The primary bioactivities screening showed that these new triterpenoids had a cytotoxic and anti-inflammation effect (Giang et al. 2022). In vivo experiment in the rat model of Parkinson's disease, lycopodium extracts also reduced the loss of dopaminergic neurons by suppressing oxidative stress and neuron inflammation (Jayaraj 2019).

In this study, two lycopodium alkaloid extracts from Vietnam were used to check the effect on the differentiation stage of primary NSCs. The data demonstrated the maintain NSCs and activating the differentiation of NSC. These results highlight the scientific evidence of these lycopodium alkaloids in application to the treatment of neuron degenerative disease.

\section{Materials and Methods}

\subsection{Plant Materials}

The whole dried plants of $H$. serrata and L. clavatum were collected from mountain regions of Vietnam. The plants were identified by the trained taxonomist. After their identification, the voucher specimens were deposited at the Museum of Biology, Faculty of Biology, University of Science, Vietnam National University, Hanoi, (accession number HNU 024659 for $L$. clavatum and HNU 024660 for $H$. Serrata.

Further, $80 \mathrm{~g}$ of whole plant powder was extracted with $\mathrm{MeOH}$ and $0.5 \% \mathrm{NaOH}$, sonicated for 10 minutes, and refluxed three times. The crude extracts of H. serrata $(18.39 \mathrm{~g})$ and L. clavatum $(18.69 \mathrm{~g})$ were dried under reduced pressure and resuspended in $200 \mathrm{ml}$ of $1 \mathrm{~N} \mathrm{HCl}$ and then partitioned with EtOAc (ratio 1:1) (Chuong et al. 2014). The final concentration of alkaloid fractions of $\mathrm{H}$. serrata and $L$. clavatum was $6.61 \mathrm{~g}$ and $5.19 \mathrm{~g}$, respectively. The alkaloid fractions were dissolved in DMSO for further study.

\subsection{Primary NSCs culture and differentiation condition}

The primary neuronal stem cells were kindly received from Animal Cell Laboratory, Center for Life Science Research (CELIFE), University of Science, Vietnam National University, Hanoi. The cells were maintained on neuropan basal medium 
Table 1 List of primers sequences

\begin{tabular}{|c|c|}
\hline Primers & Sequences \\
\hline \multirow{2}{*}{ Nestin } & F: 5'- GGTGGGCAGCAACTGGC -3' \\
\hline & R: 5'- CAGCTTGGGGTCAGGAAAGCC -3' \\
\hline \multirow{2}{*}{ Pax 6} & F: 5'- CTGGAGAAAGAGTTTGAGAGG -3' \\
\hline & R: 5'- CTG CTGCTG ATA GGAATGTG -3' \\
\hline \multirow{2}{*}{$M A P 2$} & F: 5'- AAGTCACTGATG GAATAAGC -3' \\
\hline & R: 5'- CTCTGCGAATTG GTTCTG -3' \\
\hline \multirow{2}{*}{$T U B B 3$} & F: 5'- GCCTCCTCTCACAAGTATG -3' \\
\hline & R: 5'- CCTCCGTATAGTGCCCTT -3' \\
\hline \multirow{2}{*}{ GAPDH } & F: 5'- GTGGCAAAGTGGAGATTGTTGCC -3' \\
\hline & R: 5'- GATGATGACCCTTTTGGCTCC -3' \\
\hline
\end{tabular}

(PAN-biotech) supplemented with 2\% B27 (without retinoic acid), $10 \mathrm{ng} / \mathrm{ml}$ bFGFvà, $10 \mathrm{ng} / \mathrm{ml}$ EGF, and $1 \%$ antibiotic mixture $(50$ $\mathrm{U} / \mathrm{ml}$ penicillin, $50 \mu \mathrm{g} / \mathrm{ml}$ streptomycin, $>1 \mathrm{ng} / \mathrm{ml}$ amphotericin B). For differentiation reduction, neurospheres were harvested on day 6 and then transferred to plates with poly-D-lysine (PDL)-coated surface containing $1 \%$ fetal bovine serum (FBS), neuropan basal medium, supplemented with mixture antibiotic and without the growth factors. All cells were culture at $37^{\circ} \mathrm{C}$ in a humidified incubator with $5 \% \mathrm{CO}_{2}$ (Zhu et al. 2019).

\subsection{Lycopodium alkaloid fraction treatment conditions}

Lycopodium alkaloid fractions were dissolved in DMSO and diluted in a growth medium to make the final $1 \%$ concentration of DMSO. For control experiments, the same volume of DMSO was added. The cytotoxic activities of isolated alkaloids were evaluated at different concentrations and determined by the Promega Cell Titer-Glo® Luminescent Cell Viability Assay kit. Primary NSCs were cultured in 96 wells of opaque black culture disk (SPL 31496). The plant extracts were added $0.044 ; 0.088 ; 0.175 ; 0.35$; $0.7 ; 1.4(\mathrm{mg} / \mathrm{ml})$ for $H$. serrata; $0.031 ; 0.063 ; 0.125 ; 0.25 ; 0.5 ; 1.0$; $2.0(\mathrm{mg} / \mathrm{ml})$ for L. clavatum for $48 \mathrm{~h}$ (Ma et al. 2013). The measure of the cell viability was followed by the instruction. Briefly, after 48 hours of treatment, the medium was replaced by CellTitter-Glo Luminescent solution, then the cells were lysis by shaker at 500 rpm in 10 minutes. The disks were rested at room temperature for 5 - 10 minutes and read the luminescent signal at $535 \mathrm{~nm}$ by a multi-plate reader (Berthold Tristar LB 942). Cell viability curves were drawn, and $\mathrm{IC}_{50}$ was calculated using GraphPad Prism software version 8 . To test the effect of alkaloid fractions in the differentiation of the primary NSCs, 5 and $10 \mu \mathrm{g} / \mathrm{ml}$ of $H$. serrata extract; 0,625 and $1,25 \mu \mathrm{g} / \mathrm{ml}$ of $L$. clavatum extract were added in the differentiation medium. The morphology was observed on day 2 and day 6. The images were captured by phase-contrast microscopy.
2.4 RNA extraction and quantitative Reverse-Transcription polymerase chain reaction ( $q R T-P C R)$

Total RNAs were extracted using the RNeasy Mini Kit (Qiagen, 74104), and cDNAs were generated by reverse transcription using the qScript cDNA (Quantabio, 95047). qRT-PCR was performed using $2 \mu \mathrm{l}$ of cDNA in $25 \mu \mathrm{lGoTaq}{ }^{\circledR}$ qPCR Master Mix (Promega). The mouse gene-specific primers were synthesized and used in the quantification of transcripts are shown in table 1.

Mouse GAPDH was used as an internal control. Real-time PCR reactions were carried out using the Applied Biosystems 7500 Real-Time PCR System. Results are expressed as fold induction in mRNA levels as calculated by the $\Delta \Delta \mathrm{CT}$ method (Livak and Schimittgen 2001).

\subsection{Statistical analysis}

Statistical analysis was performed using the paired t-tests for in vitro data and the nonparametric Mann-Whitney test for in vivo data with GraphPad Prism version 8.0 software (GraphPad Software). Results are presented as means \pm SEM (standard error of the mean). Data with a $P$ value less than 0.05 were considered significant.

\section{Results and Discussion}

3.1 Effect of alkaloid fractions on the morphology of neural stem cells

In the current study, the primary mouse neural stem cells (NSCs) were received from Animal Cell Laboratory, CELIFE, VNU University of Science, Hanoi. To confirm the stemness of cultured cells, semi-quantify RT-PCR was performed to check the expression of neural progenitor/stem cells marker genes. As shown in Figure $1 \mathrm{~A}$, the neurospheres were formed, and the high 
expression of Nestin and PAX6 was detected but not for other marker genes for differentiation. This result indicated that these cells had the neural stem cell status.

Cytotoxicity of two alkaloid fractions of $H$. serrata and $L$. clavatum was calculated as the percentage of cell viability by using CellTiter-Glo ${ }^{\circledR}$ assay. The multiple concentrations of alkaloid fractions from $H$. serrata $(0.044 ; 0.088 ; 0.175 ; 0.35 ; 0.7 ; 1.4$ $\mathrm{mg} / \mathrm{ml})$ and $L$. clavatum $(0.031 ; 0.063 ; 0.125 ; 0.25 ; 0.50 ; 1.0 ; 2.0$ $\mathrm{mg} / \mathrm{ml}$ ) were used to treat NSCs at period of $48 \mathrm{~h}$ incubation (Figure 2). Cell viability analyses designated that alkaloid fractions caused development inhibition of NSCs in dose-dependent manners. At low concentrations, both $H$. serrata and $L$. clavatum extracts had little effect on cell viability. Further, the concentration level of $0.35 \mathrm{mg} / \mathrm{ml}$ of $H$. serrata and $0.25 \mathrm{mg} / \mathrm{ml}$ of $L$. clavatum started cell survival inhibition. Both plant extracts showed a less cytotoxic effect on the primary NSCs with the $\mathrm{IC}_{50}$ value of 0.56 $\mathrm{mg} / \mathrm{ml}$ (H. serrata) and $0.50 \mathrm{mg} / \mathrm{ml}$ (L. clavatum).

A

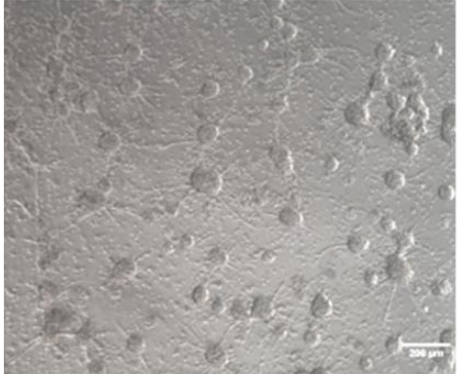

2 div

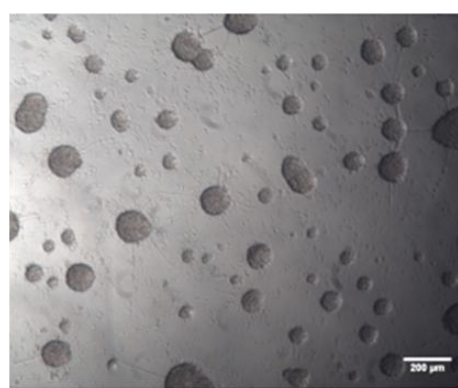

4 div

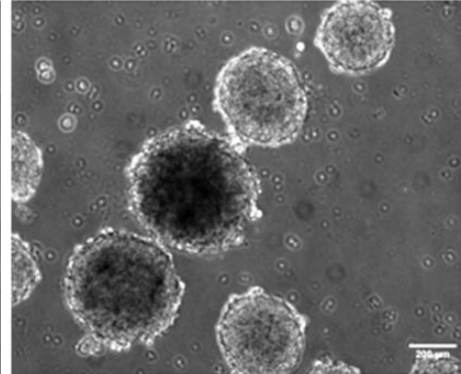

6 div

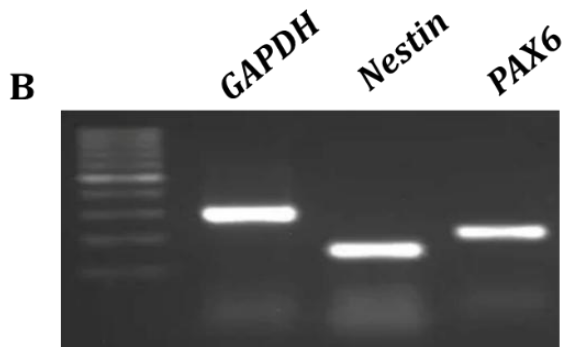

Figure 1 Identification of the mouse primary NSCs. A - Representative images of neuro-sphere in continuous culture at 2, 4, 6 days in vitro. Scale bar $=200 \mu \mathrm{m}$. B - The expression of neural stem cell marker genes, Nestin, PAX6, was determined by RT-PCR.

\section{Hupezia serrata}

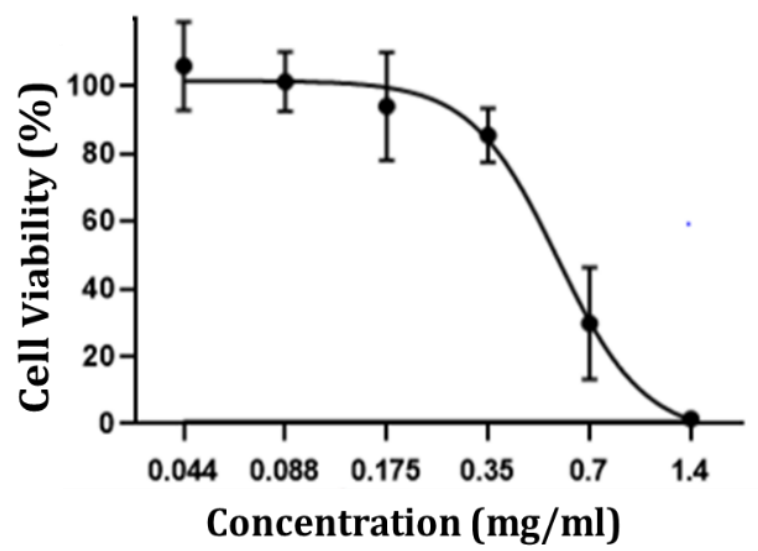

Lycopodium clavatum

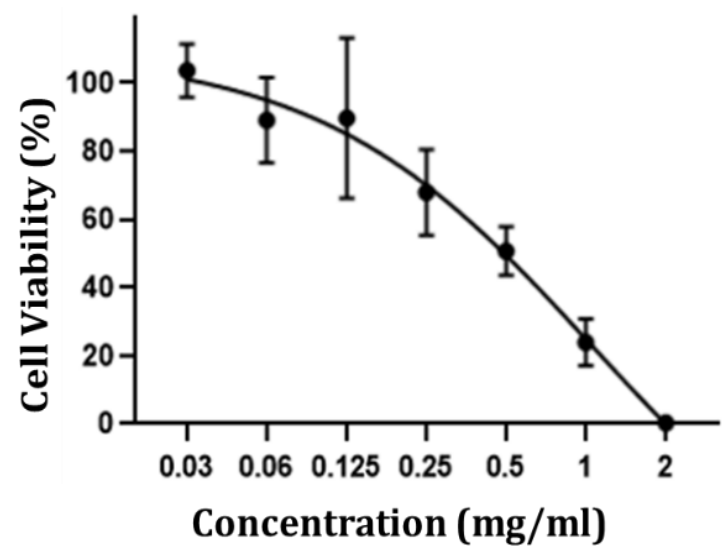

Figure 2 Toxicity effect of the Lycopodium alkaloid fractions on primary mouse neural stem cells after $48 \mathrm{~h}$ post-treatment. A - Hupeziaserrata $\mathrm{IC}_{50}=0.56 \mathrm{mg} / \mathrm{ml}$. B -Lycopodium clavatum $\mathrm{IC}_{50}=0.50 \mathrm{mg} / \mathrm{ml}$.

Journal of Experimental Biology and Agricultural Sciences http://www.jebas.org 


\section{Hupezia serrata}
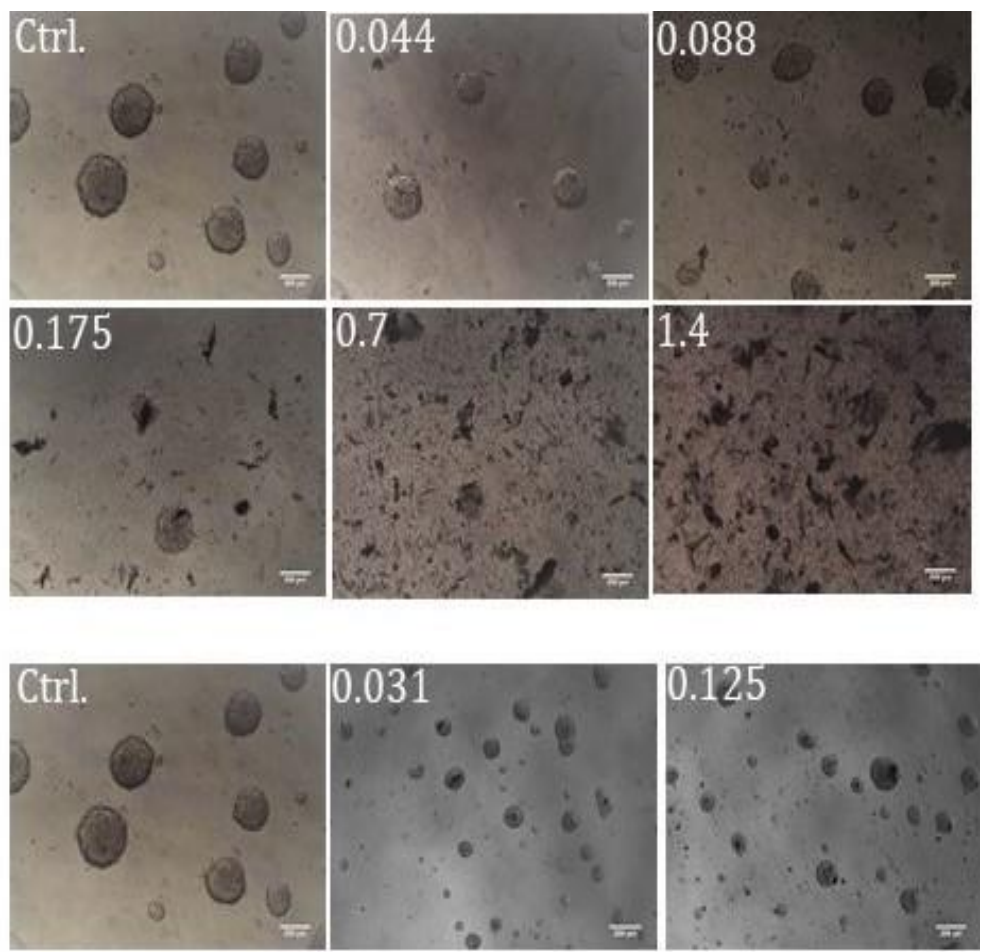

\section{Lycopodium clavatum}
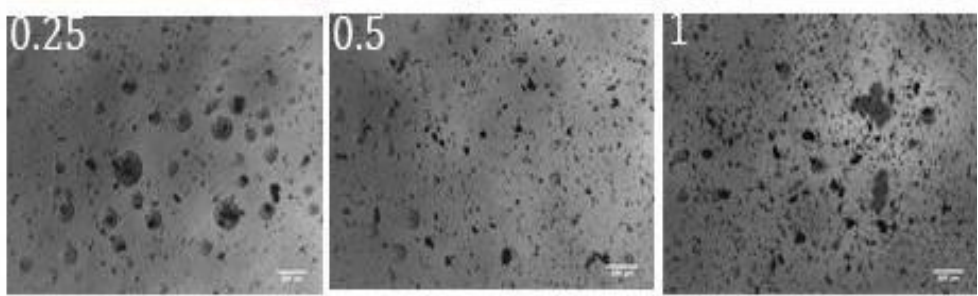

Figure 3 Imagines of the morphological changes induced by the alkaloid fraction of various concentrations of $H$. serrataand L. clavatum on the primary NSCs after $48 \mathrm{~h}$ post-treatment. The cells were observed by using a phase-contrast microscopy. Scale bar $=200 \mu \mathrm{m}$.

To identify the effect of two alkaloid fractions, changes in cell morphology were also observed. The primary NSCs were exposed to multiple concentrations of alkaloid fractions of $H$. serrata and L. clavatum and observed under a phase-contrast microscope. $48 \mathrm{~h}$ of post-treatment, the primary NSCs indicated the most prominent effects on both alkaloid fractions. Results presented in figure 3 showed that the number of cell death increased correspondingly with an increase of alkaloid fraction concentrations. At the lower concentration, $0.044 \mathrm{mg} / \mathrm{ml}$ of $H$. serrata extract and $0.031 \mathrm{mg} / \mathrm{ml}$ of $L$. clavatum extract, the neurospheres remained forming. Nevertheless, at the higher concentrations, the shape of the primary NSCs reduced in size, became shrunken, and broke into small pieces. Furthermore, at the highest concentration $(1.4 \mathrm{mg} / \mathrm{ml}$ for H.serrata and 1.0 $\mathrm{mg} / \mathrm{ml}$ for $L$. clavatum), the primary NSCs turned to black, completely fractured, and showed signs of detachment from the surface of the wells denoting cell death. Untreated primary NSCs (control) had no change in morphology.

\subsection{Effect of Alkaloid fractions extracted from $H$. serrata and L.clavatum on the differentiation of NSCs}

To identify bioactivities related to the differentiation of primary NSCs, we determined the effect of the alkaloid fractions under the differentiation condition. The primary NSCs were differentiated in the presence of DMSO or Lycopodium alkaloids extract dissolved in DMSO, and the morphology was observed on day 2 and day 6 . Here, 5 and $10 \mu \mathrm{g} / \mathrm{ml}$ of alkaloid fraction from H.serrata; 0.625 and $1.25 \mu \mathrm{g} / \mathrm{ml}$ of alkaloid fraction from L.clavatum were added to the differentiation medium. These concentrations did not show any effect on the viability of primary NSCs in the differentiation medium. Similarly, no neuron cell morphological difference was reported between the control and treated cells on day 2 (Figure 4). However, after 6 days of post-treatment, the cells treated by H.serrata extract were in more density than control at both concentrations (5 and $10 \mu \mathrm{g} / \mathrm{ml}$ ). On the contrary, the cells treated with L. clavatum have less density as compared to the control at 

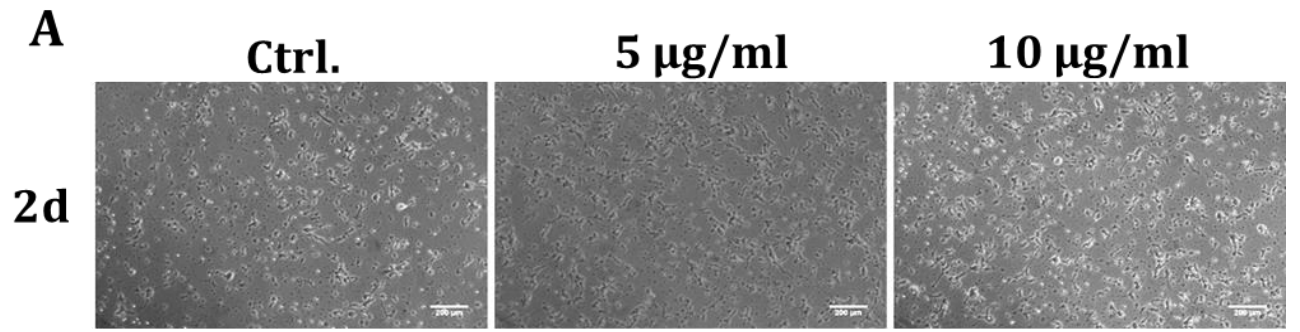

6d
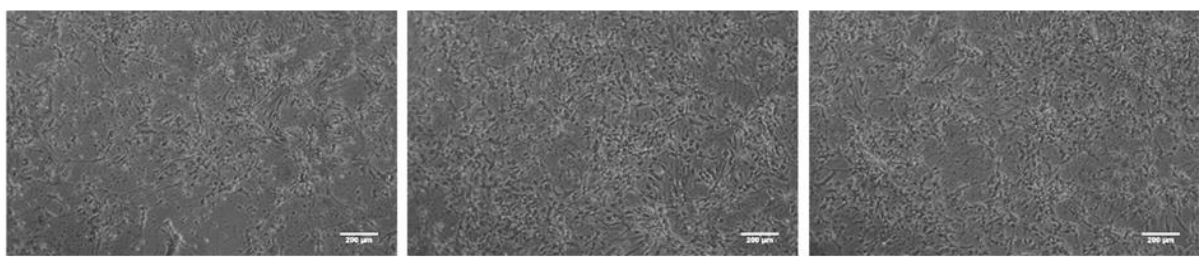

B

Ctrl.
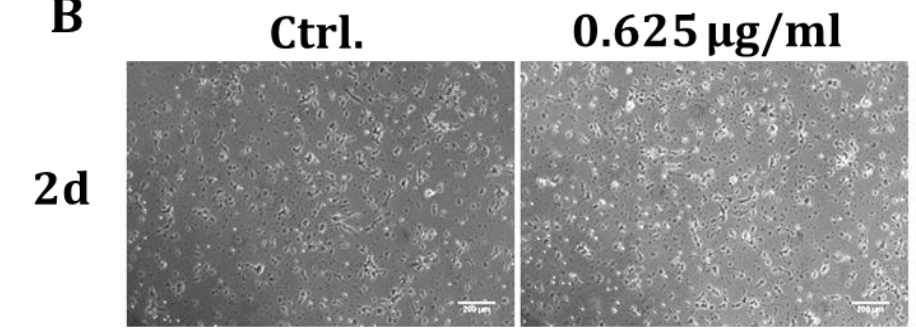

$1.25 \mu \mathrm{g} / \mathrm{ml}$

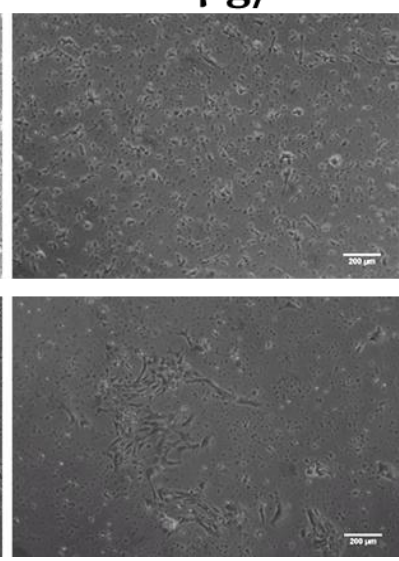

Figure 4 Lycopodium alkaloid fractions affect to differentiation of primary NSCs. A, B - Primary NSCs were exposed to alkaloid fractions from $H$. serrataand L. clavatum under the differentiation condition. The images were takenon day 2 and day 6 . Scale bar $=200 \mu \mathrm{m}$

0.625 and $1.25 \mu \mathrm{g} / \mathrm{ml}$. These results indicated that the alkaloid fraction of H.serrata promoted the differentiation of primary NSCs, while the alkaloid fraction of $L$. clavatum seemed to suppress the differentiation of primary NSCs.

\subsection{Effect of Lycopodium alkaloid fractions on the expression of genes related to the differentiation of NSCs}

Findings of the current study suggested that both alkaloid fractions from H.serrata and L.clavatum affect to differentiation of primary NSCs, the expression of marker genes of neural stem cells and neuronal cells were also determined in the current study. Nestin and PAX6 genes were selected as markers for neural stem cells and TUBB3 and MAP2 genes were selected as markers for neuron cells. As shown in Figure 5A, the expression of Nestin and PAX6 was reduced in treated cells compared to the untreated sample after 2 days of post-treatment and remained till day 6. NSCs have the potential to differentiate into neurons and form a functional neural network. The differentiated neuronal marker TUBB3gene (early neuron) significantly increased after 6 days of post-treatment with alkaloid fraction from H.serrata extract. Moreover, the MAP2 gene, a neuron-specific cytoskeletal protein also showed high upregulated on day 6 in comparison to the control sample. These results demonstrated that the alkaloid fraction from H.serrata treatment promotes NSCs differentiation to neurons.

In the case of primary NSCs exposed to alkaloid fraction from $L$. clavatum under differentiation condition, the expression of Nestin gene had no significant difference to control, and PAX6 was increased on day 6. On the contrary, the expression of neuronal marker genes (TUBB3 and MAP2) was decreased in comparison to control (Figure 5B). These data suggested that the alkaloid fraction from L. clavatum could maintain stemness. 
A
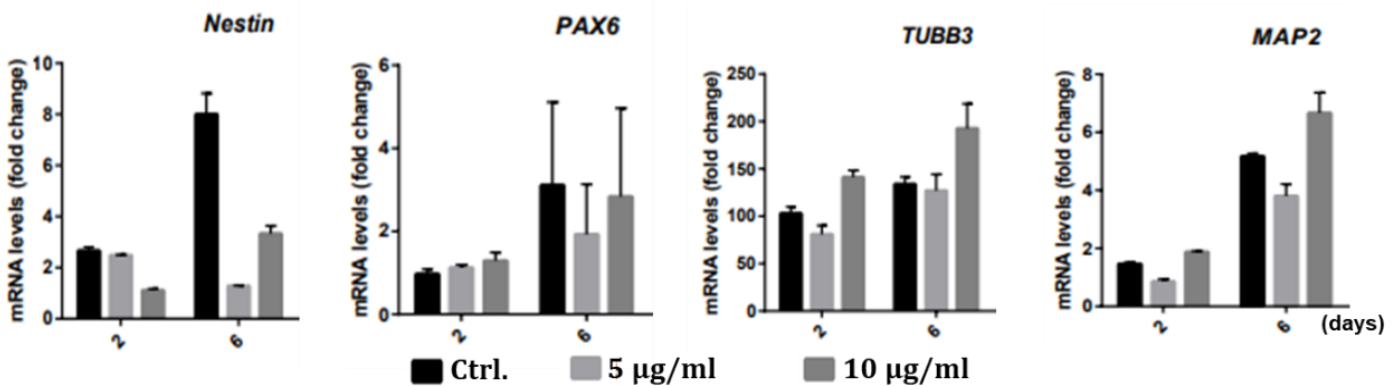

B
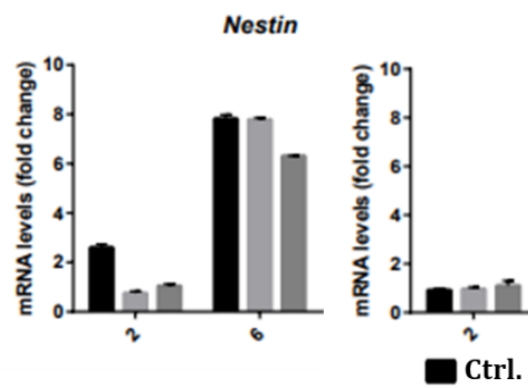

PAX6

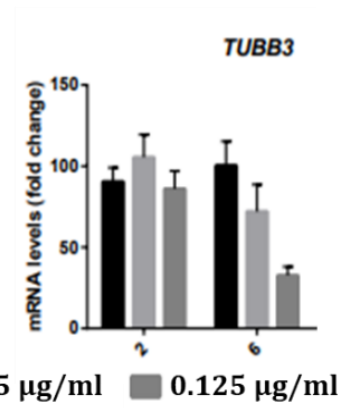

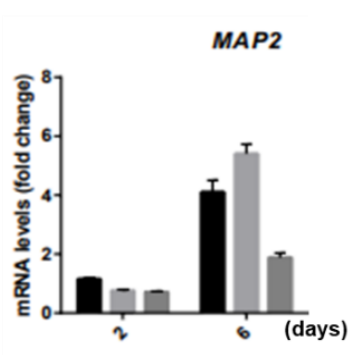

Figure 5 qRT-PCR analysis for mRNA expression levels of the Lycopodium alkaloid fractions affect the expression of genes related to differentiation of NSCs. A, B - mRNA levels of NSCs treated with alkaloid fraction of H. serrataand alkaloid fraction of L. clavatum were quantified by qRT-PCR. Data are presented as mean \pm SEM.

\section{Discussion}

In this study, we examined the effect of alkaloid fraction from two Lycopodiaceae collected in Vietnam on the primary NSCs. First, we evaluated the effect of these extracts on the morphology of primary NSCs and then determined the cytotoxicity when the cells were exposed to the plant extracts. We found that these extracts affect the primary NSCs on dose-manner. The value of $\mathrm{IC}_{50}$ of H.serrata and L.clavatum was $0.56 \mathrm{mg} / \mathrm{ml}$ and $0.50 \mathrm{mg} / \mathrm{ml}$, respectively. This data showed a less cytotoxic effect of two lycopodium alkaloid fractions on the primary NSCs.

It has been reported that lycopodium alkaloids were used in the treatment of neurogenerative diseases such as Ma et al. (2013) demonstrated that Huperzine A promoted the proliferation of cultured mouse embryonic hippocampal NSCs. Huperzine A protects the neural stem cells against $A \beta$-induced apoptosis in neural stem cells and microglia co-culture system by inhibiting cell apoptosis through restraining microglia's inflammatory response induced by $\mathrm{A} \beta 1-42$ (Zhu et al. 2015). In Panama, the Lycopodiaceae family has been screened for their anticholinesterase inhibitory and antioxidant activities, and the results showed that only $L$. clavatum subsp. clavatum showed strong AChE inhibition (Calderón et al. 2013). $\alpha$-onocerin was isolated from the chloroform extract of L.clavatum was shown as an acetylcholinesterase inhibitor (Orhan et al. 2003). Similarly,
Hanif et al. (2015) reported that L. clavatum on memory functions and cerebral blood flow in memory-impaired rats. There are several papers published about the bioactivities of Lycopodiaceae extract from Vietnam. Chuong et al. (2014) isolated six Lycopodium alkaloids from Vietnamese H. squarrosa, among them, lycosquarosine $\mathrm{A}$ and acetylaposerratinine have shown strong AchE inhibitory activity (Chuong et al. 2014). Two other Lycopodium alkaloids were identified and named fawcettidine, and 12-epilycodoline $\mathrm{N}$-oxide from $H$. phlegmaria was collected from Vietnam. The compounds showed moderately AChE inhibitory effects (Thu et al. 2019). However, there is a lack of study on the bioactivities of these Lycopodiaceae extracts on the NSCs and their differentiation. Here, under the differentiation condition, the primary NSCs were treated with $H$. serrata derived alkaloid fraction showed the capability into mature neurons as indicated by the increased gene expression level of early neuron $T U B B 3$ and neuron-specific cytoskeleton $M A P 2$ but not to neural stem cell marker Nestin and PAX6 gene. On the other hand, the alkaloid fraction from L. clavatum showed opposite bioactivities in the differentiation condition. With increased neural stem cell marker genes and decreased differentiation neuron marker genes compared to control, L. clavatum alkaloid fraction potential played a role in stemness-maintaining function. Taken together, these results established that alkaloid fraction from H.serrata promoted differentiation of the primary NSCs to neurons, and L.clavatum extract had a capacity of stemness maintaining. 


\section{Conclusions}

In summary, our study calculated that the value of $\mathrm{IC}_{50}$ of $H$. serrata and L. clavatum was $0.56 \mathrm{mg} / \mathrm{ml}$ and $0.50 \mathrm{mg} / \mathrm{ml}$, respectively. The lycopodium alkaloid from $H$. serrata showed the effect on the differentiation of NSCs to neuron cells, and the lycopodium alkaloid from $L$. clavatum has the potential to maintain the stemness of primary NSCs.

\section{Acknowledgments}

Special thanks to MSc. Khanh Thi Van Bui, Center for Life Science Research (CELIFE), University of Science, Vietnam National University, Hanoi for providing mouse neural stem cells.

\section{Author's contributions}

H.N.T. Tran, H.T.T. Nguyen, D.H. Nguyen, T.D. Nguyen performed the experiments. T.T. La and K.T.T. Nguyen collected the plants and identified them, Q.H. Nguyen and L.T. Nguyen critically revised the manuscript for important intellectual content. M.H.T. Hoang developed experimental concepts and designs, analyzed and interpreted data, and wrote the manuscript. All authors have read and agreed to the published version of the manuscript.

\section{Conflict of interest}

The authors declare no conflict of interest.

\section{Fund source}

This research was funded by Vietnam National University, Hanoi (VNU) under Project QG.18.10.

\section{References}

Ayer, W.A. (1991). The lycopodium alkaloids. Natural Product Reports 8(5), 455-63. https://doi.org/10.1039/NP9910800455.

Calderón, A.I., Simithy-Williams, J., Sanchez, R., Espinosa, A., Valdespino, I., \& Gupta, M.P. (2013). Lycopodiaceae from Panama: a new source of acetylcholinesterase inhibitors. Natutal Product Research, 27(4-5), 500-505. https://doi.org/10.1080/ 14786419.2012.701217.

Chuong, N.N., Huong, N.T., Hung, T.M., \& Luan, T.C. (2014). Anti-cholinesterase activity of lycopodium alkaloids from Vietnamese Huperzia squarrosa (Forst.) Trevis. Molecules, 19(11), 19172-9. https://doi.org/10.3390/molecules191119172.

Dymek, A., Widelski, J., Wojtanowski, K.K., Vivcharenko, V., Przekora, A., \& Mroczek, T. (2021). Fractionation of lycopodiaceae alkaloids and evaluation of their anticholinesterase and cytotoxic activities. Molecules, 26(21), 6379. doi: 10.3390/molecules26216379.

Friedli, M.J., \& Inestrosa, N.C. (2021). Huperzine A and its neuroprotective molecular signaling in Alzheimer's Disease. Molecules, 26(21), 6531. https://doi.org/10.3390/molecules26216531.

Fujita, S. (2003). The discovery of the matrix cell, the identification of the multipotent neural stem cell, and the development of the central nervous system. Cell Structure and Function, 28(4), 205-28. https://doi.org/10.1247/csf.28.205.

Gage, F.H. (2000). Mammalian neural stem cells. Science, 287(5457), 1433-1438. https://doi.org/10.1126/science.287.5457.1433.

Giang, V.H., Thuy, L.T., Hanh, T.T.H., Cuong, N.X., et al. (2022). Cytotoxic and nitric oxide inhibitory activities of triterpenoids from Lycopodium clavatum L. Natural Product Research 6:1-8. doi: 10.1080/14786419.2021.2024824.

Hanif, K., Kumar, M., Singh, N., \& Shukla, R. (2015). Effect of homeopathic Lycopodium clavatum on memory functions and cerebral blood flow in memory-impaired rats. Homeopathy, 104(1), 24-28. https://doi.org/10.1016/j.homp.2014.08.003.

Jalal, F.Y. (2019). Lycopodium attenuates loss of dopaminergic neurons by suppressing oxidative stress and neuroinflammation in a rat model of Parkinson's Disease. Molecules, 24(11), 2182. https://doi.org/10.3390/molecules24112182.

Kitajima, M., \& Takayama, H. (2011). Lycopodium alkaloids: isolation and asymmetric synthesis. Alkaloid synthesis, 309, 1-31. https://doi.org/10.1007/128_2011_126.

Li, J., Meng, X., Li, F., Liu, J., Ma, M., \& Chen, W. (2021). Huperzine A combined with hyperbaric oxygen on the effect on cognitive function and serum hypoxia-inducible factor- $1 \alpha$ Level in elderly patients with vascular dementia. American Journal of Translational Research, 13(6), 6897-6904.

Livak, K.J., \& Schmittgen, T.D. (2001). Analysis of relative gene expression data using real-time quantitative PCR and the 2(-Delta Delta C(T)) Method. Methods, 25(4), 402-408. https://doi.org/10.1006/meth.2001.1262.

Ma, T., Gong, K., Yan, Y., Zhang, L., et al. (2013) Huperzine A promotes hippocampal neurogenesis in vitro and in vivo. Brain Research, 1506, 35-43. https://doi.org/10.1016/ j.brainres.2013.02.026.

Ma, X., \& Gang, D.R. (2004). The Lycopodium alkaloids. Natural Product Reports, 21(6), 752-72. https://doi.org/10.1039/B409720N.

Nakatomi, H., Kuriu, T., Okabe, S., Yamamoto, S., et al. (2002) Regeneration of hippocampal pyramidal neurons after ischemic 
brain injury by recruitment of endogenous neural progenitors. Cell, 110(4), 429-41. https://doi.org/10.1016/S0092-8674(02)00862-0.

Noctor, S.C., Flint, A.C., Weissman, T.A., Dammerman, R.S., \& Kriegstein, A.R. (2001). Neurons derived from radial glial cells establish radial units in neocortex. Nature, 409(6821), 714-720. https://doi.org/10.1038/35055553.

Orhan, I., Terzioglu, S., \& Sener, B. (2003). Alpha-onocerin: an acetylcholinesterase inhibitor from Lycopodium clavatum. Planta Medica, 69(3), 265-267. https://doi.org/10.1055/s-2003-38489.

Russo, I., Barlati, S., \& Bosetti, F. (2011). Effects of neuroinflammation on the regenerative capacity of brain stem cells. Journal of Neurochemistry, 116(6), 947-956. https://doi.org/10.1111/j.1471-4159.2010.07168.x.

Siengalewicz, P., Mulzer, J., \& Rinner, U. (2013). Lycopodium alkaloids synthetic highlights and recent developments. The Alkaloids Chemistry and Biology, 72, 1-151. https://doi.org/10.1016/B978-0-12-407774-4.00001-7.

Takouda, J., Katada, S., \& Nakashima, K. (2017). Emerging mechanisms underlying astrogenesis in the developing mammalian brain. Proceedings of Japan Academy, Series B, 93(6), 386-398. https://doi.org/10.2183/pjab.93.024.

Temple, S. (2001). The development of neural stem cells. Nature, 414(6859), 112-117. https://doi.org/10.1038/35102174.

Thu, D.K., Vui, D.T., \& Tung, B.T. (2019). Two Lycopodium Alkaloids from the aerial parts of Huperzia phlegmaria. Pharmacognosy Research, 11(4), 396-399. http://dx.doi.org/10.4103/pr.pr_82_19.

Wang, C.Y., Zheng, W., Wang, T., Xie, J.W., et al. (2011). Huperzine A activates $W n t / \beta$-catenin signaling and enhances the nonamyloidogenic pathway in an Alzheimer transgenic mouse model. Neuropsychopharmacology, 36(5), 1073-1089. https://doi.org/10.1038/npp.2010.245.

Wang, Z.F., \& Tang, X.C. (2007). Huperzine A protects C6 rat glioma cells against oxygen-glucose deprivation-induced injury. FEBS Letters, 581(4), 596-602. https://doi.org/10.1016/j.febslet.2007.01.016.

Yang, G., Wang, Y., Tian, J., \& Liu, J.P. (2013). Huperzine A for Alzheimer's disease: a systematic review and meta-analysis of randomized clinical trials. PLoS One, 8(9), e74916. https://doi.org/10.1371/journal.pone.0074916.

Zangara, A. (2003). The psychopharmacology of huperzine A: an alkaloid with cognitive enhancing and neuroprotective properties of interest in the treatment of Alzheimer's disease. Pharmacology Biochemistry and Behavior, 75(3), 675-86. https://doi.org/10.1016/S0091-3057(03)00111-4.

Zhang, H.Y., Yan, H., \& Tang, X.C. (2008). Non-cholinergic effects of huperzine A: beyond inhibition of acetylcholinesterase.

Cellular Molecular Neurobiology, 28(2), 173-83. https://doi.org/10.1007/s10571-007-9163-z.

Zhu, N., Lin, J., Wang, K., Wei, M., Chen, Q., \& Wang, Y. (2015). Huperzine A protects neural stem cells against A $\beta$-induced apoptosis in a neural stem cells and microglia co-culture system. International Journal of Clinical \& Experimental Pathology, 8(6), 6425-33. PMC4525852.

Zhu, X., Yan, J., Bregere, C., Zelmer, A., et al. (2019). RBM3 promotes neurogenesis in a niche dependent manner via IMP2IGF2 signaling pathway after hypoxic-ischemic brain injury. Nature Communications, 10, 3982. https://doi.org/10.1038/s41467019-11870-x 